\title{
Diagnosis and Management of Hoarseness in Developing Country
}

\author{
Waheed Atilade Adegbiji ${ }^{1}$, Shuaib Kayode Aremu ${ }^{2}$, Clement \\ Nwawolo $^{3}$, Oyebanji Anthony Olajuyin ${ }^{1}$, Fatai Olatoke ${ }^{4}$ \\ ${ }^{1}$ Ekiti State University Teaching Hospital, Nigeria \\ ${ }^{2}$ Federal Teaching Hospital Ido-Ekiti/Afe-Babalola University Ado-Ekiti, \\ Nigeria \\ ${ }^{3}$ Lagos University Teaching Hospital, Nigeria \\ ${ }^{4}$ Federal Medical Centre Lokoja, Kogi State, Nigeria
}

\section{OPEN ACCESS}

Citation: Adegbiji W.A., Aremu S.K., Nwawolo C, Olajuyin O.A, Olatoke F. (2018) Diagnosis and Management of Hoarseness in Developing Country. Open Science Journal 3(2)

Received: $7^{\text {th }}$ February 2018

Accepted: $17^{\text {th }}$ May 2018

Published: $31^{\text {st }}$ May 2018

Copyright: () 2018 This is an open access article under the terms of the Creative Commons Attribution License, which permits unrestricted use, distribution, and reproduction in any medium, provided the original author and source are credited.

Funding: The author(s) received no specific funding for this work

Competing Interests: The author have declared that no competing interests exists.
*Corresponding Author: Shuaib Kayode Aremu: shuaib.aremu.gmail.com

\section{Abstract}

Background: Hoarseness/dysphonia of voice is the most common symptom of laryngeal disorder regardless of its pathology.

This study aimed at determining the sociodemographic profile, aetiology, predisposing factors, clinical profile and management of hoarseness.

Materials and Methods: This study was a prospective study carried out on all patients who presented hoarseness of voice via the Ear, Nose, and the Throat at the department of a tertiary institution in Nigeria.

The study was carried out between October 2015 to September 2017. Data were obtained from patients who gave consent by using pre tested interviewer assisted questionnaire. All the data obtained were analyzed using SPSS version 16.0.

Results: Prevalence of hoarseness was $2.4 \%$. There were $58.4 \%$ males with male to female ratio being 1.5:1. Housewives were involved 27.6\%, Singers 21.5\%, Teachers $17.3 \%$, and Clergy $13.1 \%$. Main causes were $96.3 \%$ organic causes and $2.8 \%$ neurological causes. Common organic causes were $36.4 \%$ acute laryngitis, $30.8 \%$ chronic laryngitis, and $15.0 \%$ vocal nodules.

Main predisposing factors were Upper respiratory tract infections $50.5 \%$, Voice abuse $33.6 \%$, and Laryngopharyngeal reflux $29.4 \%$. 
Commonest duration of the hoarseness prior to presentation were $>12$ months in $29.4 \%$ and 6-9 months in 27.1\%. Main clinical features were hoarseness $78.5 \%$, catarrh/cold $73.4 \%$, sensation of lump in the throat $62.6 \%$, and cough $55.6 \%$. Prior medications before presentation to otorhinolaryngologist were local herb $84.6 \%$, over the counter medication $48.6 \%$, and health care center $38.3 \%$. Specialist care was conservative/medical treatment $77.6 \%$, surgical intervention $20.1 \%$, and referral $2.3 \%$.

Conclusion: Prevalence of hoarseness of voice was high with associated presentation to the specialist. Organic causes are the commonest with predominant inflammatory origin. Laryngeal neoplasm with associated malignancy was significant in a numbers of patients.

Keywords: Hoarseness, Dysphonia, Laryngeal diseases, Laryngoscopy, Speech disorder

\section{Introduction}

Hoarseness/dysphonia of voice is defined as a voice disorder which is characterized by changes in the vocal quality, frequency, intensity, or effort that limits communication or causes a negative impact on voice-related quality of life through a self-perceived decrease in the individual's physical, emotional, social, or economic status [1]. Voice is said to hoarse when the quality is coarse, scratchy, rough, breathy or harsh [2,3]. Hoarse voice disorders also have a significant influence on vocational, social, and emotional adjustments of the sufferers.

Epidemiologic studies of hoarseness have shown that it affects approximately $6 \%$ of children under 14 years of age, and 3-9\% of the adult population [4]. This also assessed the prevalence of the condition among different age groups and occupational groups.

Some of the predisposing factors to hoarseness include vocal abuse, smoking, and frequent upper respiratory tract infections. Hoarseness may be an early, warning signal as it is the most common symptom of laryngeal pathology ranging from mild laryngeal inflammation to more severe laryngeal malignancy. Aetiopathological factors causing hoarseness include laryngeal irritation, infective laryngitis (acute and chronic), benign non neoplastic nodular lesions, laryngeal papillomatosis, neoplastic vocal cord lesions, neuromuscular disorders, and laryngeal cancers [5].

Several factors are involved in the development of hoarseness in a classification method. They can be divided into organic (structural changes of the vocalization system into malformation, traumatic, inflammatory/ infectious and neoplastic/tumor aetiologies), neurologic (innervation and muscular control of vocalization system, from respiration to voice production deficits caused by 
lesions in the central or peripheral nervous system), and functional (aphonia, psychogenic, hyperfunctional and hypofunctional) categories $[6,7]$.

In otorhinolaryngological clinical practice, appropriate treatment of diseases requires accurate diagnosis of the underlying cause of hoarseness. Examination and evaluation of the pharynx, larynx, head, and neck seems to be essential. Although the location of these structures often inhibits direct observation, simple techniques may be used under clinical conditions for their evaluation among which fibreoptic laryngoscopy is a valid noninvasive and anesthesia-free approach. In comparison with indirect laryngoscopy, this method is easier, is of greater accuracy, and can be used for the diagnosis of different causes of hoarseness $[8,9]$.

This study aimed at determining sociodemographic profile, aetiology, predisposing factors, clinical profile, and management of hoarseness of voice. This is to ensure that early diagnosis and appropriate intervention can be made. This practice will reduce morbidity and mortality in the patients.

\section{Materials and Methods}

This was a prospective hospital-based study of patients with complaints of hoarseness at the Ear, Nose, and Throat at the department of Ekiti State University Teaching Hospital, Ado Ekiti, Nigeria. The present study was carried out from October 2015 to September 2017. Patients were attended to at the Otorhinolaryngology outpatient department with history of hoarseness. Consent was obtained from patients and those who gave consent were enrolled into this study.

Complete medical and personal history including sociodemographic features was taken. Detailed history on the hoarseness onset, duration, precipitating factors, and relieving and aggravating factors were taken and documented. General clinical and otorhinolaryngology, head and neck examination was done for each of the patients. Detailed oral and oropharyngeal examination were performed. All the patients were subjected to indirect laryngoscopy and diagnostic flexible laryngoscopy.

Based on the findings, imaging studies such as Chest x-ray, Computerized tomography scan, and Magnetic resonance imaging were requested. Specimen obtained from examination under anaesthesia and biopsy was sent for histopathological examination.

Data were obtained by using pretested interviewers assisted questionnaire. All data obtained were documented.

All data were collated and analyzed using SPSS version 16.0. The data were expressed by frequency table, percentage, bar charts, and pie charts.

Ethical clearance for this study was sought for and obtained from ethical committee of the institution. 


\section{Results}

A total of 8,917 patients were seen during the study period out of which 214 patients had hoarseness of voice. The prevalence of hoarseness in this study was $2.4 \%$.

Age group distribution is shown in Figure 1. All age group was involved in this study. The most commonly affected age group was 21-30 years whereby 68 $(31.8 \%)$ patients were affected.

Sociodemographic features among the patients were demonstrated in Table 1. Among the 214 patients, $125(58.4 \%)$ were males, 89 (41.6\%) were females, with male to female ratio being 1.5:1. Urban dwellers were the majority and constituted 118 (55.1\%). $193(90.2 \%)$ patients were the majority and they belong to the Christian faith. Based on level of education, secondary school certificate holders and graduates from tertiary institutions constituted the majority and were $86(40.2 \%)$ and $73(34.1 \%)$ respectively. Married $135(63.1 \%)$ and single 63 $(29.4 \%)$ were the main marital status that has affected the study population. Patients having hoarseness of voice belongs to different occupations. Housewives were $59(27.6 \%)$, Singers $46(21.5 \%)$, Teachers $37(17.3 \%)$, and Clergy 28 $(13.1 \%)$.

Aetiology of hoarseness among the patients is illustrated in Table 2. Functional causes were seen in $2(0.9 \%)$ patients, organic causes were seen in 206 $(96.3 \%)$ patients, and neurological causes were seen in $6(2.8 \%)$ patients. Common organic causes were identified in $78(36.4 \%)$ of the patients. These include acute laryngitis, $66(30.8 \%)$ chronic laryngitis (of which 3 [1.4\%] patients had tuberculous laryngitis), $32(15.0 \%)$ vocal nodules, and 12 (5.6\%) trauma. Vocal cord neoplasm was diagnosed in 18 (8.4\%) patients with laryngeal papillomatosis in $5(2.3 \%)$ patients and laryngeal carcinoma in $13(6.1 \%)$ patients. Unilateral vocal cord palsy was seen in $6(2.8 \%)$ patients. Also, left sided vocal cord palsy in $5(2.3 \%)$ patients was more common than right sided vocal cord palsy in $1(0.5 \%)$ patient. In $2(0.9 \%)$ idiopathic and in $4(1.9 \%)$ goiter, post thyroidectomy were the causes of vocal cord palsy in this study.

Predisposing factors among the patients is shown in Table 3. Main predisposing factors for the pathologies in this study were Upper respiratory tract infections in $108(50.5 \%)$ patients, Voice abuse in $72(33.6 \%)$ patients, and Laryngopharyngeal reflux in $63(29.4 \%)$ patients. Others were Atmospheric pollution in $53(24.8 \%)$ patients and Smoking in $44(20.6 \%)$ patients.

Duration of hoarseness prior to presentation is illustrated in Figure 2. Complaints with duration of hoarseness ranged from 1 month to more than 12 months. Commonest duration of the complaint of hoarseness prior to presentation were greater than 12 months in 63 (29.4\%), 6-9 months 58 (27.1\%), and 9-12 months $46(21.5 \%)$.

Presenting complaints among the patients is demonstrated in Table 4 . We found associated complaints among the patients with hoarseness in 168 (78.5\%). They include cold 157 (73.4\%), lump sensation in the throat 134 (62.6\%), cough 119 (55.6\%), and Hawking 103 (48.1\%). Other complaints include 93 (43.5\%) retrosternal pain, $88(41.1 \%)$ dysphagis, and $87(40.7 \%)$ of the patients.

Management of hoarseness among the patients is shown in Table 5. The type of medications prior to presentation at the ear, nose, and throat clinic were local 
herb 181 (84.6\%), over the counter medication $104(48.6 \%)$, and health care center $82(38.3 \%)$. Treatment in ear, nose, and throat department were medical treatment with antibiotics, anti-inflammatory agents, vocal rest/hygiene, and voice rest with resolution of symptoms 166 (77.6\%). Surgical intervention included direct laryngoscopy with biopsy, chemoradiation for early laryngeal carcinoma, excision of vocal nodules, excision of laryngeal polyp and clearance of laryngeal papilloma $43(20.1 \%)$, and referral to psychologist and speech pathologist $5(2.3 \%)$.

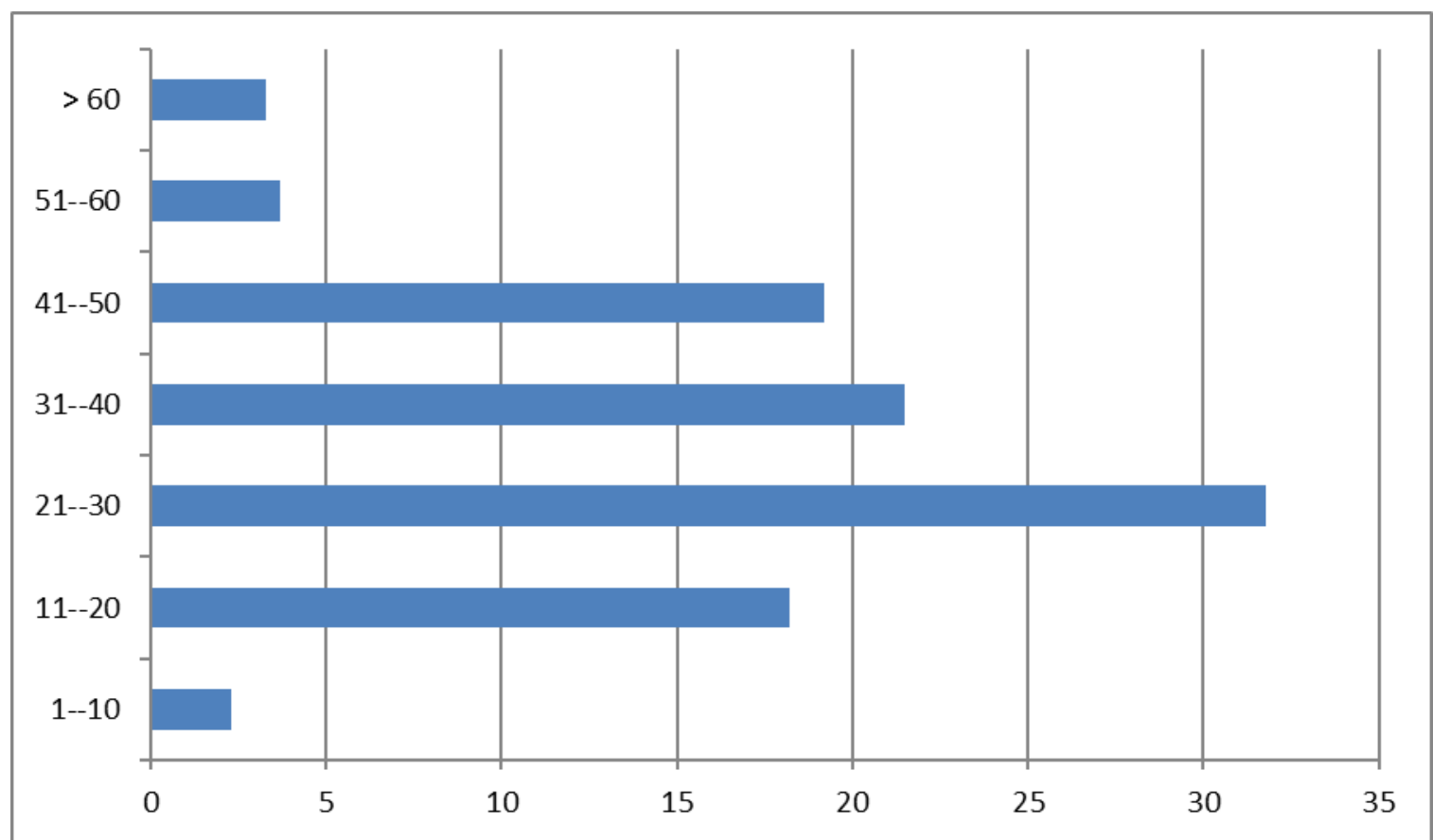

Figure 1. Age group distribution of the patients

Table 1. Sociodemographic features of the patients

\begin{tabular}{|l|l|l|}
\hline Sociodemographic features & Number & Percentage (\%) \\
\hline Gender & & \\
Male & 125 & 58.4 \\
Domale & 89 & 41.6 \\
Urban & 118 & 55.1 \\
Rural & 96 & 44.9 \\
Religion & & \\
Christianity & 193 & 90.2 \\
Islamic & 21 & 9.8 \\
Education level & & \\
None & 13 & 6.1 \\
Primary & 42 & 19.6 \\
Secondary & 86 & 40.2 \\
Tertiary & 73 & 34.1 \\
Marital status & & 29.4 \\
Single & 63 & \\
\hline
\end{tabular}




\begin{tabular}{|l|l|l|}
\hline Married & 135 & 63.1 \\
Divorce & 16 & 7.5 \\
Occupation & 59 & 27.6 \\
House-wife & 12 & 5.6 \\
Businessman & 14 & 6.5 \\
Student & 28 & 13.1 \\
Clergy & 37 & 17.3 \\
Teacher & 46 & 21.5 \\
Singer & 18 & 8.4 \\
Others & & \\
\hline
\end{tabular}

Table 2. Aetiology of hoarseness among the patients

\begin{tabular}{|l|l|l|}
\hline Aetiology & Number & Percentage (\%) \\
\hline Functional causes & 2 & 0.9 \\
Acute laryngitis & 78 & 36.4 \\
Chronic laryngitis & 66 & 30.8 \\
Vocal nodules & 32 & 15.0 \\
Vocal cord palsy & 6 & 2.8 \\
Trauma & 12 & 5.6 \\
Laryngeal papillomatosis & 5 & 2.3 \\
Laryngeal carcinoma & 13 & 6.1 \\
\hline & & \\
\hline
\end{tabular}

Table 3. Predisposing factors among the patients

\begin{tabular}{|l|l|l|}
\hline Predisposing factors & Number & Percentage (\%) \\
\hline Laryngopharyngeal reflux & 63 & 29.4 \\
Voice abuse & 72 & 33.6 \\
Alcohol & 43 & 20.1 \\
Upper respiratory infection & 108 & 50.5 \\
Smoking & 44 & 20.6 \\
Atmospheric pollution & 53 & 24.8 \\
None & 42 & 19.6 \\
\hline & & \\
\hline
\end{tabular}




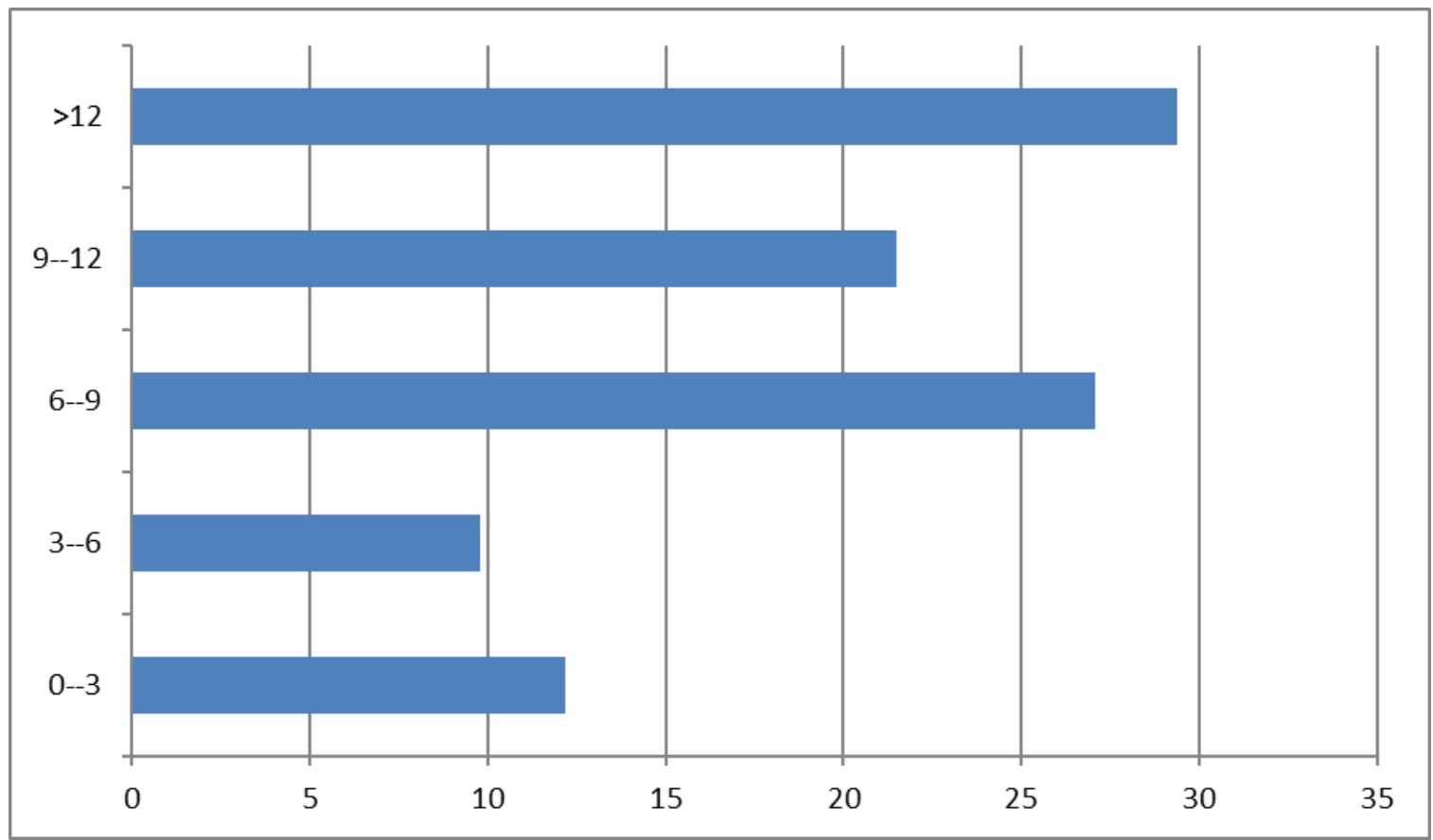

Figure 2. Duration of hoarseness prior to presentation

Table 4. Presenting complaints among the patients

\begin{tabular}{|l|l|l|}
\hline Presenting complaints & Number & Percentage (\%) \\
\hline Changes in voice/hoarseness & 168 & 78.5 \\
Lump sensation in the throat & 134 & 62.6 \\
Cold/Catarrh & 157 & 73.4 \\
Cough & 119 & 55.6 \\
Hawking & 103 & 48.1 \\
Itchy throat & 87 & 40.7 \\
Stridor & 46 & 21.5 \\
Retrosternal pain & 93 & 43.5 \\
Dysphagia & 88 & 41.1 \\
Vocal fatigue & 83 & 38.8 \\
Trauma to neck & 12 & 5.6 \\
Neck swelling & 28 & 13.1 \\
Aphonia & 4 & 1.9 \\
\hline
\end{tabular}

Table 5. Management of hoarseness among the patients

\begin{tabular}{|l|l|l|}
\hline Management of hoarseness & Number & Percentage (\%) \\
\hline Prior treatment & & \\
Local herbs & 181 & 84.6 \\
Over the counter medication & 104 & 48.6 \\
Health care center & 82 & 38.3 \\
Otorhinolaryngology treatment & & \\
Medical & 166 & 77.6 \\
Surgical & 43 & 20.1 \\
Referral & 5 & 2.3 \\
\hline
\end{tabular}




\section{Discussion}

Hoarseness of voice is one of the common manifestation of laryngeal disease in otorhinolaryngological practice worldwide. The care has caused a lot of challenges in medical practice for centuries [10]. Hoarseness is rarely life threatening but may signify the presence of more serious laryngeal disorder such as malignancy or airway compromise and should not be underestimated [11,12]. Prevalence of hoarseness in the studied patients was $2.4 \%$. Prevalence of hoarseness in this study is higher than findings in previous studies [13,14].

In this study, there was male predominance. This finding is in accordance with record from other studies $[15,16]$. The highest prevalence was recorded among young age group (21-30 years) in this study. It is noted that individuals in younger age group are more ambitious, active, and they use their vocal skills more than other age groups. There was high prevalence of hoarseness of voice among housewives, singers, and teachers in this study. Hoarseness is known to be due to laryngeal disorder, with occupational abuse or excessive vocal use as in teachers, clergy, choir/singers, actor and housewives etc. The observations in this study are similar to record in other reports $[17,18]$.

In this present study, there were associated laryngeal as well as extra laryngeal symptoms. The commonest laryngeal symptom was hoarseness of voice which was the most common presenting complaint. Further complaints were catarrh/cold, lump sensation in the throat, cough, and hawking in this study.

Duration of hoarseness of voice at presentation in this study ranges from 1 month to more than 12 months. Majority of the studied patients were presented with hoarseness duration of greater than 12 months. This finding is similar to record seen in other studies $[15,16]$.

Commonest predisposing factors for hoarseness of voice were found to be upper respiratory infection, vocal abuse, and laryngopharyngeal reflux disorder. This is in accordance with findings in other studies [19-20]. In this present study, smoking and alcohol were less common predisposing factors compared to other previous study [16]. The intake is lower among these patients due to campaign against and because of religious background based on reduced smoking and alcohol intake in the present study.

In this study, commonest causes of hoarseness of voice were organic causes. This is followed by neuromuscular causes with least causes in functional causes. Functional causes of hoarseness of voice was predominant in previous studies $[21,22]$. Of the organic causes, acute laryngitis was the most common causes of hoarseness of voice seen in this study. This finding is similar to report from other studies [23]. This high prevalence is attributed to frequent upper respiratory tract infections and exposure to atmosphere pollution from industrialization and urbanization.

Chronic laryngitis is the second most common cause of organic causes of hoarseness observed in this study. Similar findings were reported in another study [24]. Contrary to these findings, chronic laryngitis was the second major causes of hoarseness of voice [25]. Specific laryngitis such as tuberculous laryngitis were not common in this research work.

Vocal nodules were noted as the third commonest cause of hoarseness in this study. This resulted from vocal abuse as one of the predominant factor causing 
vocal nodules in this study. This pathology may be reversed by conservative therapy like voice rest and voice therapy.

In this study, malignancy disorder were common than benign laryngeal tumour. Similar results were demonstrated in other studies [15].

Of the neuromuscular causes, vocal cord palsy causes of hoarseness of voice are secondary to idiopathic and post thyroidectomy in the studied patients.

Functional causes of hoarseness of voice occurred when there is no clinical structural abnormality in the patients. In this study, all the patients were secondary to psychogenic types as shown in previous study [26].

In this present study, most of the participants believed hoarseness of voice was a minor feature that is self-relieving or can be cured with local herbs with gin. Over the counter, medication was their second line of treatment while health care center was the last resort for the patients. In this study, majority of the patients were treated conservatively by voice therapy and/or medical treatment $[27,28]$. Surgical intervention for hoarseness of voice was indicated for neoplastic conditions or cases that failed conservative treatment as documented in other studies [29-31].

\section{Conclusion}

Prevalence of hoarseness of voice was high with associated late presentation in this study. The most common pathology involved was organic causes with inflammatory origin. Laryngeal neoplasm with malignancy was diagnosed in a significant number of patients. Early presentation and diagnosis are advised to reduce the avoidable morbidity and mortality.

\section{Acknowledgements}

The authors are most grateful to Ekiti State University Teaching Hospital and all the patients who participated in this study.

\section{References}

1. Schwartz SR, Cohen SM, Dailey SH, Rosenfeld RM, Deutsch ES, Gillespie MB, et al. Clinical practice guideline: hoarseness (dysphonia). Otolaryngol Head Neck Surg. 2009;141(3 Suppl 2):S1-S31.

2. Mc Glashan J, Disorders of the voice. In:Gleeson M,editor.Scott- Browns otorhinolaryngology Head and Neck Surgery.7th edn.London:Hodder Arnold;2008.p.2192-94.

3. Sataloff RT, Spiegel RJ, Hawkshaw M. Voice disorders. Med Clin North Am. 1993;77(3):551-570.

4. Carding P. Voice Pathology in the United Kingdom. BMJ. 2003;327:514-5.

5. Dettelbach M, Eibling DE, Johnson JT. Hoarseness. From viral laryngitis to glottic cancer. Postgrad Med. 1994, Apr; 95(5):143-6.

6. Reymond H, Colton , Janina K, Casper , Leonard R. Understanding Voice Problems; A Physiological Perspective For Diagnosis and Treatment. 3rd Ed. Lippincott Williams and Wilkins; 2006.

7. Probst R, Iro H, Grevers G. Basic Otorhino- laryngology. 2nd ed. 2006. pp. 385-96.

8. Holsinger FC, Kies MS, Weinstock YE, Lewin JS, Hajibashi S, Nolen DD, et al. Examination of the larynx and pharynx. New Engl J Med. 2008;358:e2. 
9. Preciado-Lopez J, Peres-Fernandez C, Calazada-Urindo M, Preciado-Ruiz P. Epidemiology study of Vice Disorder Among Teaching Professionals of La Rioja, Spain. J Voice. 2008;22(4):489 508.

10. Saudi S. Benign lesions of the vocal cards in different ages: prospective study of 60 cases. Jour of Med Sc \& Tech; September 2013 2(3); Page No: 130 -134.

11. Nwaorgu OG, Onakoya PA, Ibekwe TS, et al. Hoarseness in adult Nigerians: A University College Hospital Ibadan experience. Niger J Med 2004;13(2):152-155.

12. Adobamen PO. Causes of Hoarseness in Benin City, Nigeria. J Otol Rhinol 2015 4:5.

13. Khurshid RS, Khan MA, Ahmad R. Clinical profile of hoarseness and its management options: A 2 years prospective study of 145 patients. International journal of phonosurgery and laryngology. 2012;2(1):23-29.

14. Hansa B et al. Hoarseness of voice: A retrospective study of 251 cases. Int J Phonosurg Laryngol 2011 Jan-June;1.

15. Batra K, Motwani G, Sagar PC. Functional voice disorders and there occurrence in 100 patients as seen on fiberoptic laryngescopy. Indian J Otolaryngol Head Neck Surg 2004; 56 (2):91-95.

16. Baitha S, Raizada RM, Singh AKK, Puttewar MP, Chaturvedi VN Clinical profile of hoarseness of voice. Indian J Otolaryngol Head Neck Surg 2002;54(1):14-18.

17. Connelly A, et al. Management of dysphonia in children. J Laryngol Otol 2009;123:642-47. 18. Carding PN, et al. The prevalence of childhood dysphonia: A cross-sectional study. J Voice 2006;20:623-30.

18. Block BB, Brodsky L. Hoarseness in children and role of LPR. Int J Pediatric Otorhinolaryngology 2007;71:1361-69. 20. Koufman JA. Gastroesophageal reflux and voice disorder. Diagnosis and treatment of voice disorders. New York-Tokyo 1995;161-75.

19. Sala E, Laine A, Simberg S, Pentti J, Suonpaa J. The prevalence of voice disorders among day care center teachers compared with nurses: a questionnaire and clinical study. J Voice. 2001;15:413-23.

20. Pal KS, Kaushal AK, Nagpure PS, Agarwal G. Etiopathological study of 100 patients of hoarseness of voice: in a rural based hospital. Indian J Otolaryngol Head Neck Surg. 2014 Jan; 66(1):40-5.

21. Banjara H, Mungutwar V, Singh D, Gupta A. Hoarseness of Voice: A Retrospective Study of 251cases. International journal of Phonosurgery and Laryngology.2011; 1(1):21-27.

22. Kumar H, S Seth S. Clinicopathological Profile Of Hoarseness Of The Voice. The Internet Journal of Otorhinolaryngology. $2010 ; 13(1): 4102$.

23. Parikh NP. Aetiological study of 100 cases of hoarseness of voice. Indian Journal of Otolaryngology.June 1991, 43(2): 71-73.

24. Gregory ND, Chandran S, Lurie D, Sataloff RT. Voice disorders in the elderly. J Voice. 2012 Mar; 26(2):254-8.

25. Dagli $\mathrm{M}$, et al. Mutational falsetto: Intervention outcome in 45 patients. J Laryngol and Otol $2008 ; 122: 277-81$.

26. Noordzij JD, et al. Evaluation of omeprazole in treatment of reflux laryngitis: A prospective, Placebo controlled, randomized, double blind study. Laryngoscope 2001;111:2147-51.

27. James A Burns, et al. Phonomicrosurgical treatment of intracordal vocal fold cyst in singers. Laryngoscope 2009;119:419-22.

28. Isa A, Sandabe MB, Ngamdu YB, Garandawa A. Hoarseness in children: An aetiological profile in North-Eastern Nigeria. Sahel medical journal 2012;15(2):64-67.

29. Okhakhu A L, Emma-Nzekwue N H. Pattern of persistent hoarseness at the University of Benin Teaching Hospital. Arch Int Surg 2015;5:69-73. 